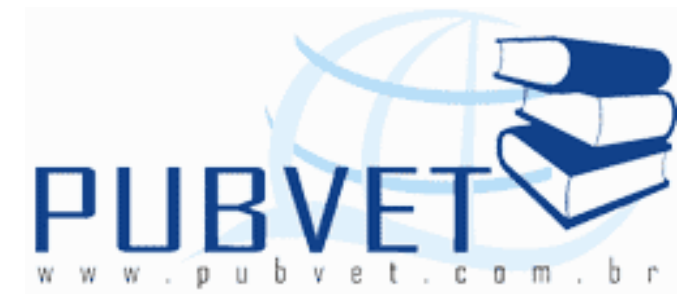

PUBVET, Publicações em Medicina Veterinária e Zootecnia.

\title{
Estudo anatômico comparativo do tubo digestório de aves de diferentes ordens
}

\footnotetext{
André Luiz Quagliatto Santos ${ }^{1}$, Mariana Batista Andrade ${ }^{3}$, Caio Henrique Ferreira², Rogério Rodrigues de Souza ${ }^{2}$, Lorena Tannús Menezes ${ }^{2}$, Sérgio Rodrigo Pereira de Oliveira ${ }^{2}$, Árthur Paulino Sanzo Kaminishi ${ }^{2}$, Liliane Rangel Nascimento ${ }^{2}$, Flávio Machado de Moraes ${ }^{1}$
}

Laboratório de Ensino e Pesquisa em Animais Silvestres - LAPAS, FAMEV/UFU, e-mail: quagliatto@famev.ufu.br 1. Docente. 2. Mestrandos. 3. Doutoranda.

\section{Resumo}

A avifauna presente no ambiente urbano tem despertado o interesse de muitos pesquisadores dentre as mais de 1800 espécies de aves encontradas no Brasil, inúmeras vem sendo criadas como animais de estimação ou mantidas em cativeiro, seja em zoológicos ou criatórios conservacionistas. 0 aparelho digestório é responsável pela manutenção da vida, sendo o tubo digestório de cada ave adaptado para processar e utilizar o mais eficientemente possível o alimento disponível em seu habitat. Com o intuito de se ampliar os conhecimentos anatômicos relativos ao tubo digestório das aves, abordou-se em um estudo comparativo, com seis exemplares de aves, representantes de cinco ordens diferentes, doadas pelo IBAMA Uberlândia/MG e enviadas ao Laboratório de Ensino e Pesquisa em Animais Silvestres (LAPAS) da UFU os animais foram fotografados, identificadas quanto 
à ordem, gênero e espécie e dissecadas, com a finalidade de se obter informações relativas à topografia, forma e dimensões dos segmentos do tubo digestório nas diferentes ordens. Ao final da pesquisa foram observadas algumas diferenças relativas à topografia, dimensões e composição do tubo digestório, entre as ordens e até mesmo entre espécies de uma mesma ordem. Concluiu-se que o estomago muscular e bem mais desenvolvido na ordem Anseriformes, e o segmento intestinal jejonunoilico é o mais longo dentre as aves estudadas. .

Palavras-chave: aves, trato gastrointestinal, anatomia.

\section{Anatomical comparative study of the digestive tube of various orders of birds}

\section{Summary}

The avifauna present in the urban environment has attracted the interest of many researchers among the more than 1800 species found in Brazil, many are being created as pets or kept in captivity, whether in zoos or farms conservationists. The digestive system is responsible for the maintenance of life, and the digestive tract of each bird adapted to process and use as efficiently as possible the food available in their habitat. In order to increase their knowledge regarding the anatomical digestive tract of birds, we dealt with in a comparative study, six specimens of birds, representing five different orders, donated by IBAMA, Uberlandia/MG Were send to the Laboratory Teaching and Research in Wildlife (LAPAS) UFUwhere the animals were photographed, identified as to the order, genus, species and dissected for the purpose of obtaining information on topography, shape and dimensions of the segments of the digestive tract in different orders. At the end of the study were observed some differences in the topography, size and composition of the digestive tract, between the orders and even between species of the same order. It was found that the stomach muscles and much more developed in the 
Anseriforms order and the jejonunoilico intestinal segment was the longest of the studied birds.

Keywords: avians, gastro intestinal tract, anatomy.

\section{INTRODUÇÃO}

A avifauna brasileira é representada por cerca de 1800 espécies reconhecidas, correspondendo a aproximadamente $60 \%$ das espécies encontradas na America do Sul. O Estado de Minas Gerais tem registradas 753 espécies de aves. Essa riqueza representa cerca de $41 \%$ da avifauna brasileiro. Em grande parte, a riqueza de espécies de aves em Minas Gerais se deve à variedade de formações vegetais no Estado, que inclui campos, matas, veredas, caatinga e cerrados. (MAPELI, 2003).

As aves presentes no ambiente urbano têm despertado o interesse de muitos pesquisadores. Estudos desenvolvidos no meio urbano têm abordado principalmente mudanças na abundância relativa e aspectos demográficos das espécies de aves em relação à urbanização. Em nível de comunidades, tem sido verificado que a riqueza de espécies de aves diminui com a urbanização, enquanto a densidade e a biomassa geralmente aumentam. Porém, níveis intermediários de desenvolvimento urbano podem aumentar a diversidade de aves (LOODI,2003).

Essas comunidades são dependentes do tamanho das cidades, como também da localização das áreas de estudos dentro dos ecossistemas humanos e, especialmente, das estruturas dos hábitats locais. De fato, diferenças de hábitats interferem diretamente na abundância de aves (Sick, 1997).

O aparelho digestório é responsável pela manutenção da vida, sendo o tubo digestório de cada ave adaptado para processar e utilizar o mais eficientemente possível o alimento disponível em seu habitat. (MAPELI, 2003)

Essa capacidade evolutiva permitiu a sobrevivência das diversas populações de aves atuais, que criaram seus nichos ecológicos próprios de acordo com os recursos alimentares disponíveis (Juniper, 1998). 
O sistema digestivo possui origem endodérmica e é formado por boca, faringe, esôfago, estômago, intestinos e ânus, além das glândulas anexas (salivares, pâncreas e fígado) (MAPELI, 2003).

Propôs-se realizar uma descrição anatômica comparativa do tubo digestório da Guiraguira (Anu-branco), Nyctibiusaethereus (urutau-pardo), Cairinamoshata (pato doméstico), Eupetonemamara (beija- flor- tesoura) e Spheniscusmagellanicus (pingüim-de-magalhães) comparando as principais características topográficas e particularidades anatômicas dos representantes.

\section{MATERIAL E MÉTODOS}

Este estudo foi realizado utilizando-se sete aves de diferentes espécies sendo um exemplar de Nyctibiusaethereus (urutau-pardo), um Guira guira (Anu-branco), um Cairinamoshata (pato doméstico), três Eupetonemamara (beija- flor- tesoura) e um Spheniscusmagellanicus (pingüim-de-magalhães) doadas pelo IBAMA - Uberlândia-MG, Minas Gerais, e enviadas ao Laboratório de Ensino e Pesquisa em Animais Silvestres (LAPAS) da Faculdade de Medicina Veterinária da Universidade Federal de Uberlândia onde foram fotografados, de modo a enfatizar aspectos individuais que diferenciam as espécies $A$ identificação das aves incluiu sua classificação quanto à ordem, gênero e espécie e foi realizada com auxílio da Lista das aves do Brasil (2011), Souza (1998) e Juniper e Pan (1998).

Cada exemplar, depois de submetido ao processo completo de dissecação e registro das informações relevantes, foi conservado em solução de formaldeído a $10 \%$ injetada em toda a musculatura das aves com seringas descartáveis de 1,5 ou $10 \mathrm{ml}$ e agulha hipodérmica $30-8$ ou agulha descartável de $13 \times 0,45 \mathrm{~mm}$ dependendo do tamanho da ave em questão. Cada ave foi dissecada a fresco, com a finalidade de manter os órgãos em suas dimensões originais, obtendo-se medidas de comprimento e diâmetro com mínima margem de erro. Concomitantemente, procedeu-se à descrição e elaboração de desenhos esquemáticos (Figuras 2,4,6,8) e fotografias (Figuras 
$1,3,5,7)$ enfocando características relativas a dimensionamento, topografia, morfologia e composição do tubo digestivo.

Quadro 1: Identificação dos exemplares de estudo quanto à ordem, espécie, nome popular, número de registro, sexo, comprimento total da ave e quantidade total do representante, nesta ordem.

\begin{tabular}{|c|c|c|c|c|c|c|}
\hline Ordem & Espécie & Nome popular & n.r & Sexo & c.t $(\mathbf{c m})$ & no.ex \\
\hline Anseriformes & Cairinamoshata & pato doméstico & 1 & $F$ & 64,40 & 01 \\
\hline Apodiformes & Eupetonemamara & $\begin{array}{l}\text { beija- } \\
\text { tesoura }\end{array}$ & $\begin{array}{l}2 \\
2.1 \\
2.2\end{array}$ & $\begin{array}{l}- \\
- \\
-\end{array}$ & $\begin{array}{l}11,73 \\
15,00 \\
15,35\end{array}$ & 03 \\
\hline Caprimulgiformes & Nyctibiusaethereus & urutau-pardo & 3 & $M$ & 41,4 & 01 \\
\hline \multirow[t]{2}{*}{ Cuculiformes } & Guiraguira & Anu-branco & 4 & $M$ & 38,50 & 01 \\
\hline & $\begin{array}{l}\text { Spheniscusmagell } \\
\text { anicus }\end{array}$ & $\begin{array}{l}\text { pingüim-de- } \\
\text { magalhães }\end{array}$ & 5 & - & 49,50 & 01 \\
\hline
\end{tabular}

c.t - comprimento total da ave (cm)

n.r - número de registro da ave

no. ex - número de exemplares da espécie

F - fêmea

M - Macho

- sexo não identificável 
O comprimento total de cada ave, que consiste na distância entre a extremidade rostral do bico até a extremidade caudal da última pena da cauda, foi obtido com o animal em decúbito dorsal e com o pescoço estendido.

Com o auxílio de um cabo de bisturi no 4, uma lâmina para bisturi no 23, uma pinça Adson e uma pinça anatômica, procedeu-se a abertura da cavidade toracoabdominal de cada exemplar a partir de uma incisão na linha mediana ventral (delimitada pelo osso esterno e cloaca) e posterior retirada do plastrão (utilizando uma cisalha $19 \mathrm{~cm}$ simples, nas aves de maior porte).

Foram adotados os seguintes pontos de referência para descrição anatômica e mensuração dos segmentos do tubo digestivo:

- Esôfago cervical: início na laringe e término na entrada da cavidade tóracoabdominal;

- Inglúvio: início na região de dilatação do esôfago cervical e término na extremidade cranial do esôfago torácico;

- Esôfago torácico: início na entrada da cavidade e término na junção com o proventrículo;

- Proventrículo: início na união com esôfago torácico e término na divisão com o ventrículo ou no istmo, quando presente;

- Ventrículo: início na união com o proventrículo e término no início da alça descendente do duodeno;

- Alça descendente do duodeno: início no piloro e término na curvatura de união com a alça ascendente do duodeno;

- Alça ascendente do duodeno: início na união com a alça anterior e término na curvatura de união ao segmento jejunoilíaco;

- Jejuno-íleo: início na união com o segmento anterior e término na divisão com coloreto, considerando-se a presença de cecos, quando existirem;

- Ceco(s): do seu ponto de inserção no segmento intestinal ao seu ápice; 
- Coloreto: início na base do(s) ceco(s), quando existirem ou do momento em que se desfazem as alças que compõem o segmento jejunoilíaco e término na cloaca.

Após descrição topográfica, o tubo digestivo foi individualizado com o auxílio de uma pinça anatômica, uma pinça hemostática, uma pinça dente de rato, uma tesoura Mayo curva e uma tesoura Metzembaum reta, divulsionando-se os tecidos que mantinham os segmentos do tubo digestivo relacionado a outros órgãos.

Cada órgão foi mensurado com um paquímetro Starret de precisão 0,05 $\mathrm{mm}$, de modo a registrar o comprimento e diâmetro dos mesmos. As medidas de diâmetro tomadas não se apresentam de maneira constante para todas as aves, uma vez que variaram de acordo com o estado de distensão do órgão no momento do óbito da ave.

Estabeleceu-se uma relação, em porcentagem média, entre o comprimento de cada segmento do tubo digestivo e o comprimento total dos exemplares de uma mesma ordem.

As informações referentes à descrição anatômica em cada ave foram anotadas em fichas individuais. (Quadro 1 a 5).

\section{RESULTADOS}

\section{Ordem Anseriformes}

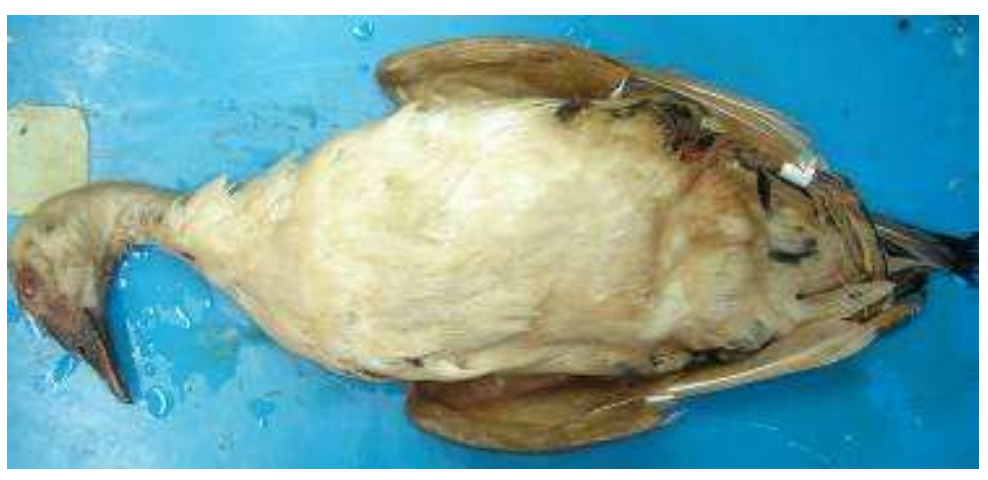

Figura 1: pato-doméstico Cairinamoshata 
O esôfago cervical inicia-se dorsalmente à traquéia, na face ventral do pescoço e logo no seu terço inicial desvia-se para a direita, mantendo-se dorsolateralmente à traquéia, até unir-se à porção torácica, a nível do primeiro par de costelas, haja visto a ausência de inglúvio. Representa 24,03\% do comprimento total do representante.

O esôfago torácico segue dorsalmente à traquéia, bifurcação traqueal e coração até o proventrículo, ao nível do terço caudal do coração e extremidade cranial do lobo hepático esquerdo. Equivale a $14,86 \%$ do comprimento total do representante.

O estômago químico é cilíndrico, situa-se dorsalmente ao lobo hepático esquerdo e ventralmente à metade caudal do lobo pulmonar esquerdo, ovário e parte do segmento jejunoilíaco. Une-se ao estômago muscular a nível da extremidade caudal do lobo hepático esquerdo e representa $11,38 \%$ do comprimento total da ave.

O ventrículo possui formato de lente biconvexa, está direcionada craniocaudalmente, ventralmente ao jejuno-íleo e oviduto. Situa-se dorsalmente ao assoalho da cavidade abdominal e a metade cranial de sua face ventrolateral direita relaciona-se ao terço caudal do lobo hepático direito. Representa 5,13\% do comprimento total da ave.

A porção inicial da alça duodenal está localizada dorsalmente à porção caudal do lobo hepático direito. A alça descendente do duodeno emerge da porção cranial da face dorsal do ventrículo, segue caudolateralmente a este e na região próxima à cloaca projeta-se dorsalmente até encostar na porção final do coloreto, unindo-se à alça ascendente do duodeno em uma curva ventral., direcionada cranialmente. Equivale a $21,27 \%$ do comprimento total da ave.

A alça ascendente do duodeno segue em direção cranial, lateralmente à porção descendente, até à nível da borda cranial do ventrículo e dorsalmente à porção cranial do lobo hepático direito, onde une-se ao segmento jejunoilíaco em uma curva dorsal. Equivale a $16,76 \%$ do comprimento total do representante. 
Jejuno-íleo está disposto como um emaranhado de alças unidas por mesentério e situadas predominantemente no antímero direito da cavidade tóracoabdominal, lateralmente ao oviduto e ventralmente aos rins. Representa $166,50 \%$ do comprimento total da ave.

A divisão entre intestino delgado e intestino grosso é feita por um par de cecos, grandes, de formato cilíndrico e diâmetro uniforme. Iniciam-se à nível do lobo renal médio esquerdo, seguem cranialmente até a nível da borda cranial do ventrículo, quando fazem uma curva para o antímero direito e passam a seguir caudalmente. Os cecos direito e esquerdo equivalem a $23,23 \%$ e $24,76 \%$ do comprimento total do representante, respectivamente.

O coloreto segue pela linha mediana da cavidade, ventralmente aos lobos renais médio e caudal e lateralmente ao oviduto, até a cloaca. Representam $8,78 \%$ do comprimento total da ave.

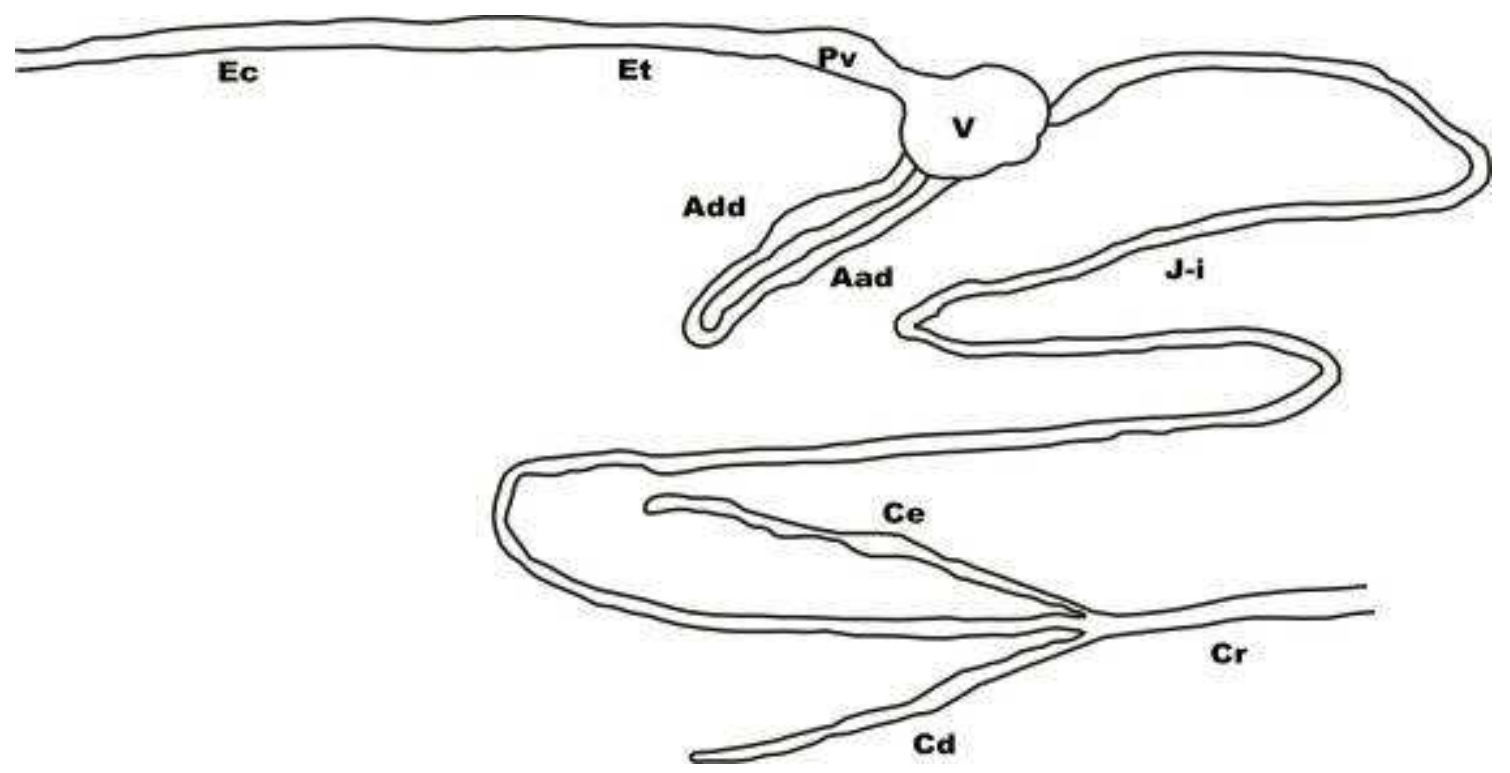

Figura 2: Tubo digestório de pato-doméstico: esôfago cervical (Ec), esôfago torácico (Et), proventrículo (Pv), Ventrículo $(\mathrm{V})$, alça descendente do duodeno (Add), alça ascendente do duodeno (Aad), jejuno-íleo (J-i), ceco direito (Cd), ceco esquerdo $(\mathrm{Ce})$ e coloreto $(\mathrm{Cr})$ 
Quadro 1: Comprimento e diâmetro dos componentes do tubo digestivo de pato-doméstico, no 1.

\begin{tabular}{|l|c|c|}
\hline \multicolumn{1}{|c|}{ Órgão } & Comprimento (mm) & Diâmetro (mm) \\
\hline Esôfago cervical & 154,80 & 10,25 \\
\hline Esôfago torácico & 95,70 & 9,80 \\
\hline Proventrículo & 73,35 & 13,85 \\
\hline $\begin{array}{l}\text { Ventrículo } * \\
\text { Alça descendente do } \\
\text { duodeno }\end{array}$ & 137,00 & 11,70 \\
\hline $\begin{array}{l}\text { Alça ascendente do } \\
\text { duodeno }\end{array}$ & $107,40 \times 30,40$ \\
\hline Jejuno-íleo & $1.072,30$ & 6,55 \\
\hline Ceco direito & 149,65 & 5,15 \\
\hline Ceco esquerdo & 159,50 & 7,15 \\
\hline Coloreto & 56,55 & 7,90 \\
\hline
\end{tabular}

* Comprimento X Largura X Espessura

\section{Ordem Apodiformes}

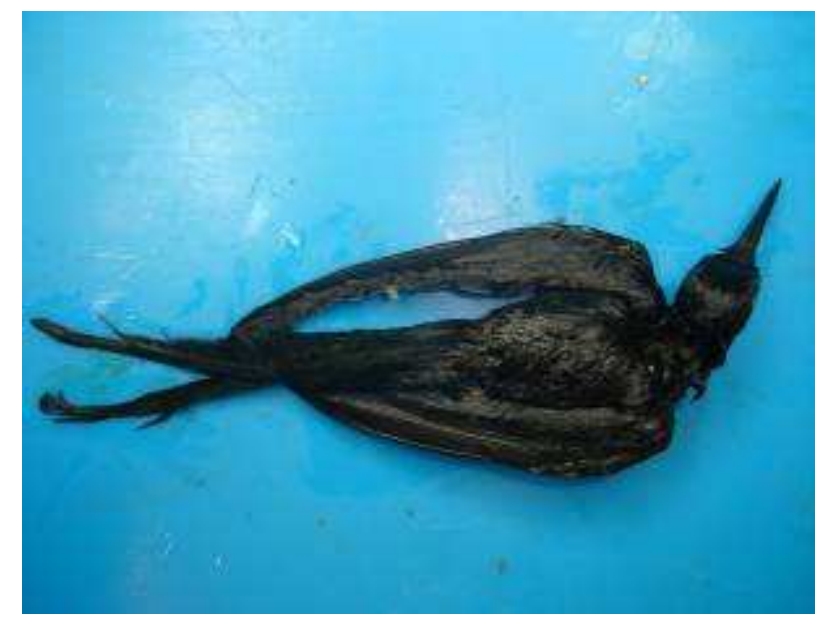

Figura 3: beija-flor-tesoura Eupetomenamacroura (Gmelin, 1788) (TROCHILIDAE).

O esôfago cervical inicia-se dorsolateralmente à traquéia, no antímero direito do pescoço e mantém essa posição durante toda sua trajetória, até a entrada da cavidade tóracoabdominal, quando une-se ao esôfago torácico, 
haja visto a ausência de inglúvio. Representa em média $11,96 \%$ do comprimento total das aves.

O esôfago torácico segue lateralmente à traquéia em posição paramediana direita, dorsalmente à bifurcação traqueal e base do coração, quando já no antímero esquerdo, une-se ao proventrículo, à nível do terço cranial do coração e extremidade cranial do lobo hepático esquerdo. Equivale a $9,08 \%$ do comprimento total dos representantes.

O estômago químico situa-se dorsalmente ao lobo hepático esquerdo e ventralmente à metade caudal dos lobos pulmonares. Possui formato fusiforme e representa $3,99 \%$ do comprimento total da espécie em estudo.

O ventrículo possui formato arredondado e equivale a 4,23\% do comprimento total da espécie. Está localizado dorsalmente ao lobo hepático esquerdo, com exceção de sua extremidade caudal e ventralmente relacionase ao coloreto.

A alça descendente do duodeno emerge da face lateral direita do ventrículo, segue caudalmente e em linha reta até próximo à cloaca, onde unese à porção ascendente através de uma curva em direção cranial. Representa $7,28 \%$ do comprimento total das aves. A alça ascendente do duodeno faz trajetória oposta, lateralmente à alça descendente do duodeno, unindo-se ao segmento jejuno-íleo ventralmente ao lobo renal cranial direito através de uma curvatura em sentido dorsolateral. Representa $7,82 \%$ do comprimento total dos representantes da ordem.

Jejuno-íleo dispõe-se em duas a três alças curtas, unidas por mesentério à face dorsal da alça duodenal e situadas predominantemente no antímero direito da cavidade, lateralmente ao coloreto e dorsalmente ao rim. Equivale a $29,98 \%$ do comprimento total das aves.

O coloreto inicia-se em através de uma curva em sentido caudal, ao nível do lobo renal cranial esquerdo, haja visto a ausência de cecos. Segue ventralmente ao rim, até a cloaca e representa $7,47 \%$ do comprimento total da espécie. 


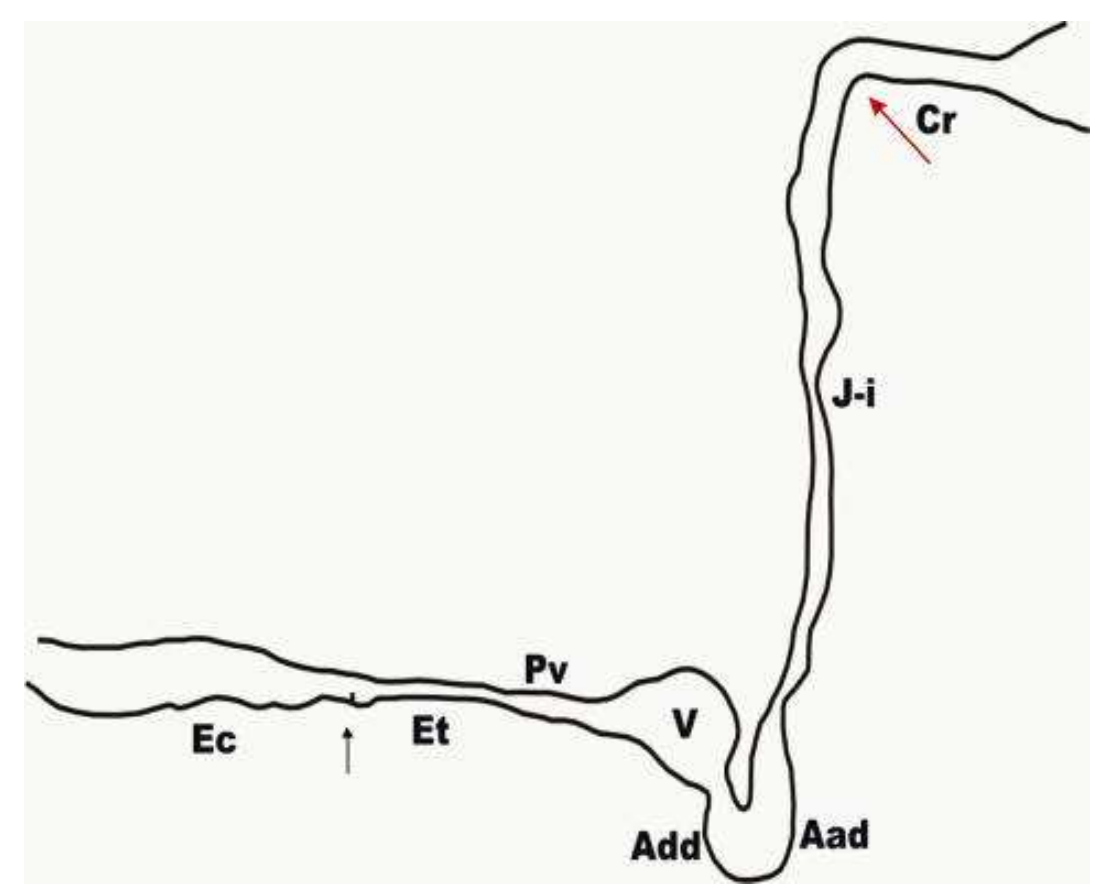

Figura 4: Representação esquemática do tubo digestório de beija-flor-tesoura esôfago cervical $(E c)$, esôfago torácico (Et), proventrículo (Pv), Ventrículo (V), alçadescendentedo duodeno (Add), alça ascendente do duodeno (Aad), jejunoíleo (J-i), ceco direito (Cd), ceco esquerdo (Ce) e coloreto $(\mathrm{Cr})$ a Transição entre o segmento cervical e o torácico do esôfago (seta preta). Divisão entre o intestino delgado e grosso (seta vermelha).

Quadro 2: Comprimento e diâmetro dos componentes do tubo digestivo de beija-flor-tesoura, $\mathrm{n} \times 2$

\begin{tabular}{|l|c|c|}
\hline \multicolumn{1}{|c|}{ Órgão } & Comprimento $(\mathrm{mm})$ & Diâmetro $(\mathrm{mm})$ \\
\hline Esôfago cervical & 15,35 & 1,75 \\
\hline Esôfago torácico & 11,60 & 1,95 \\
\hline Proventrículo & 5,85 & 3,05 \\
\hline Ventrículo & \multicolumn{2}{|c|}{$5,80 \times 5,05 \times 3,65$} \\
\hline Alça descendente do duodeno & 9,85 & 3,70 \\
\hline Alça ascendente do duodeno & 11,20 & 2,20 \\
\hline Jejuno-íleo & 41,65 & 2,80 \\
\hline Coloreto (Intestino grosso) & 10,25 & 2,45 \\
\hline
\end{tabular}


Quadro 3: Comprimento e diâmetro dos componentes do tubo digestivo de beija-flor-tesoura, no 2.1

\begin{tabular}{|l|c|c|}
\hline \multicolumn{1}{|c|}{ Órgão } & Comprimento $(\mathrm{mm})$ & Diâmetro $(\mathrm{mm})$ \\
\hline Esôfago cervical & 18,05 & 1,40 \\
\hline Esôfago torácico & 11,75 & 1,00 \\
\hline Proventrículo & 5,25 & 2,00 \\
\hline Ventrículo & \multicolumn{2}{|c|}{$7,00 \times 4,95 \times 2,95$} \\
\hline $\begin{array}{l}\text { Alça descendente do } \\
\text { duodeno }\end{array}$ & 11,45 & 2,95 \\
\hline $\begin{array}{l}\text { Alça ascendente do } \\
\text { duodeno }\end{array}$ & 11,35 & 4,40 \\
\hline $\begin{array}{l}\text { Jejuno-íleo } \\
\begin{array}{l}\text { Coloreto (Intestino } \\
\text { grosso) }\end{array}\end{array}$ & 37,30 & 1,60 \\
\hline
\end{tabular}

Quadro 4: Comprimento e diâmetro dos componentes do tubo digestivo de beija-flor-tesoura, n० 2.2

\begin{tabular}{|l|c|c|}
\hline \multicolumn{1}{|c|}{ Órgão } & Comprimento $(\mathrm{mm})$ & Diâmetro $(\mathrm{mm})$ \\
\hline Esôfago cervical & 16,55 & 3,45 \\
\hline Esôfago torácico & 14,30 & 1,15 \\
\hline Proventrículo & 5,40 & 2,25 \\
\hline Ventrículo & \multicolumn{2}{|c|}{$4,75 \times 4,75 \times 4,65$} \\
\hline $\begin{array}{l}\text { Alça descendente do } \\
\text { duodeno }\end{array}$ & 8,95 & 2,10 \\
\hline $\begin{array}{l}\text { Alça ascendente do } \\
\text { duodeno }\end{array}$ & 9,80 & 2,75 \\
\hline $\begin{array}{l}\text { Jejuno-íleo } \\
\begin{array}{l}\text { Coloreto (Intestino } \\
\text { grosso) }\end{array}\end{array}$ & 31,60 & 1,70 \\
\hline
\end{tabular}




\section{Ordem Caprimulgiformes}

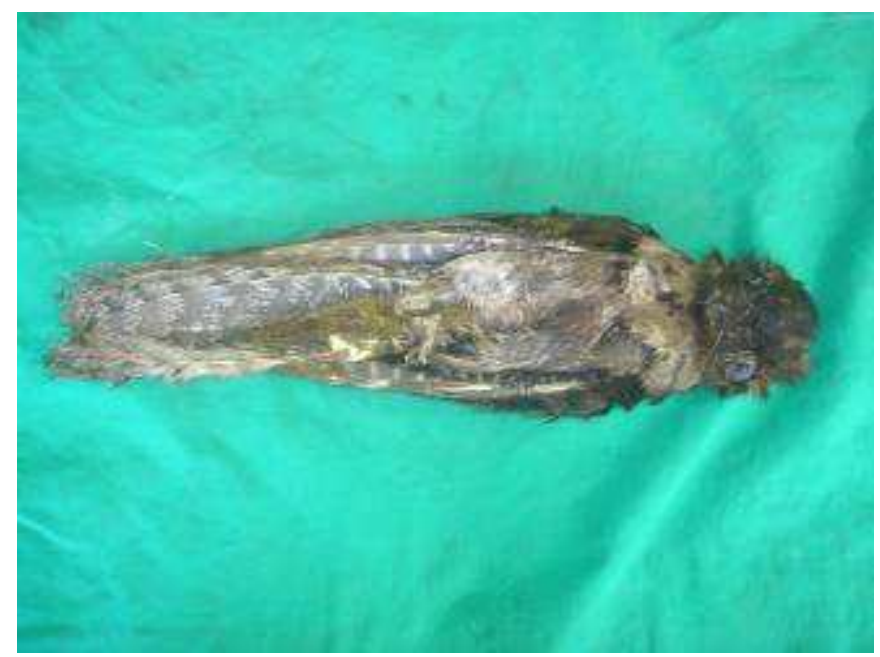

Figura 5: urutau-pardo NyctibiusaethereusWied, 1820

(NICTIBIIDAE)

O esôfago cervical é significativamente aderido à pele e mais comprido que o esôfago torácico. Segue toda sua trajetória pelo lado direito do pescoço, dorsolateralmente à traquéia, até a entrada da cavidade tóracoabdominal, onde se une à porção torácica, haja visto a ausência de inglúvio. Representa $14,55 \%$ do comprimento total da ave.

O esôfago torácico, igualmente relacionado à traquéia, se torna mais calibrosoà nível da bifurcação traqueal. Segue dorsalmente a esta, base do coração e ventralmente aos lobos pulmonares, unindo-se ao proventrículoà nível do terço cranial do coração. Equivale a $7,65 \%$ do comprimento total do representante.

O proventrículo possui formato cilíndrico, diferindo do esôfago torácico basicamente pelo maior diâmetro. Está situado ventralmente à porção caudal dos lobos pulmonares e dorsalmente à grande parte da face dorsal do coração e terço inicial do lobo hepático esquerdo.A porção caudal de sua face ventrolateral direita se relaciona com a porção inicial do lobo hepático direito e parte acessória do mesmo. Representa 3,92\% do comprimento total da ave.

O estômago muscular é arredondado e une-se ao proventrículo a nível do terço médio do fígado. Situa-se dorsalmente à metade caudal dos lobos 
hepáticos e ventralmente emaranhado de alças intestinais. Equivale a $6,18 \%$ do comprimento total do representante.

O duodeno inicia-se na porção cranial da face dorsolateral direita da moela, através da alça descendente do duodeno que segue caudoventralmente ao lobo renal médio direito até o terço final do lobo renal caudal direito, através de uma curva em direção cranial se une à porção ascendente do duodeno. Representa $10,77 \%$ do comprimento total da ave.

A alça ascendente do duodeno faz exatamente a trajetória oposta da porção descendente, lateralmente à esta, até as proximidades da região dorsocaudal do ventrículo, onde em uma curva lateral, se une ao segmento jejuno-íleo. Equivale a $6,26 \%$ do comprimento total do representante.

Jejuno-íleo tem início ventralmente ao testículo e lobo renal cranial esquerdos e está frouxamente disposto em alças, distribuídas na cavidade, ventralmente aos rins. Este segmento representa $41,88 \%$ do comprimento total da ave.

A delimitação entre jejuno-íleo e coloreto é feita por um par de cecos compridos, direcionados cranialmente e dispostos lateralmente ao íleo, um a cada lado do segmento e intimamente ligados a este por mesentério. Os cecos direito e esquerdo equivalem a $8,70 \%$ e $8,05 \%$ do comprimento total do representante, respectivamente.

O coloreto segue ventralmente aos lobos médios e caudais do rim pela linha mediana até a cloaca. Representa $13,65 \%$ do comprimento total da ave. 


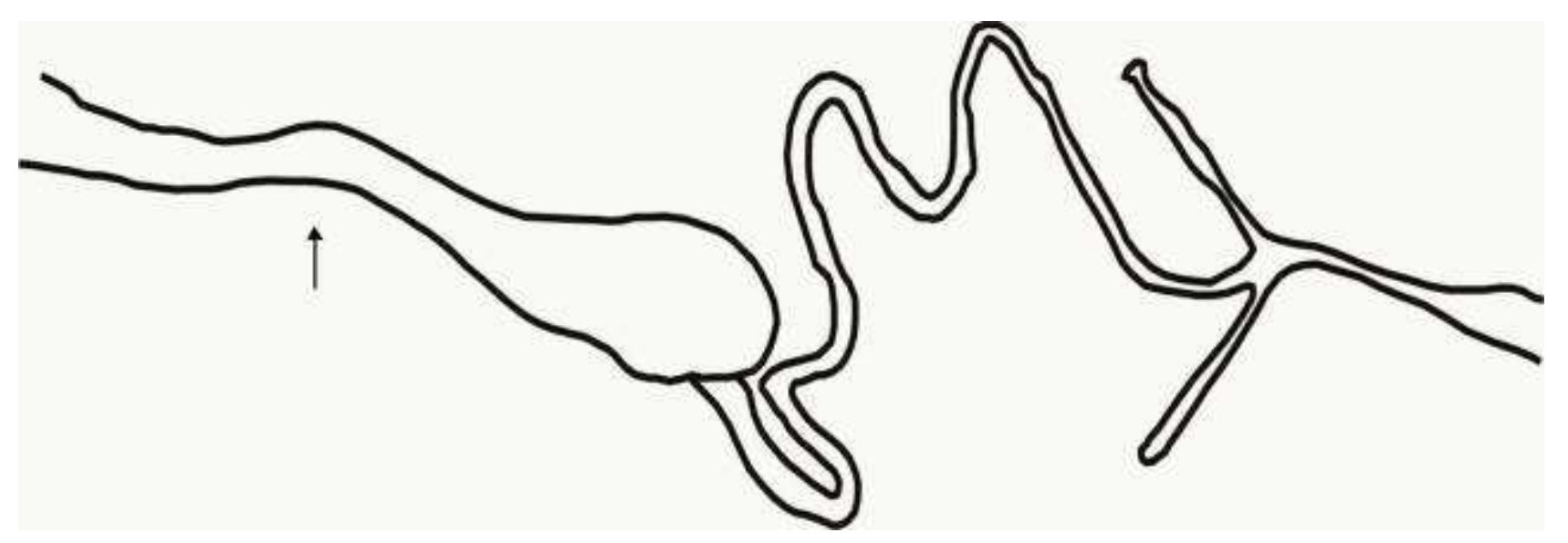

Figura 6: Representação esquemática do tubo digestório de urutau-pardo. Transição entre esôfago cervical e esôfago torácico (seta preta).

Quadro 4:Comprimento e diâmetro dos componentes do tubo digestivo urutau-pardo, n० 3

\begin{tabular}{|l|c|c|}
\hline \multicolumn{1}{|c|}{ Órgão } & Comprimento ( mm) & Diâmetro (mm) \\
\hline Esôfago cervical & 60,25 & 11,40 \\
\hline Esôfago torácico & 31,70 & 10,40 \\
\hline Proventrículo & 16,25 & 14,25 \\
\hline $\begin{array}{l}\text { Ventrículo } \\
\text { Alça descendente do } \\
\text { duodeno }\end{array}$ & 44,60 & 5,70 \\
\hline $\begin{array}{l}\text { Alça ascendente do } \\
\text { duodeno }\end{array}$ & 25,95 & 5,25 \\
\hline Jejuno-íleo & 173,40 & 2,95 \\
\hline Ceco direito & 36,05 & \\
\hline Ceco esquerdo & 33,35 & 2,70 \\
\hline Coloreto & 56,55 & \\
\hline
\end{tabular}




\section{Ordem Cuculiformes}

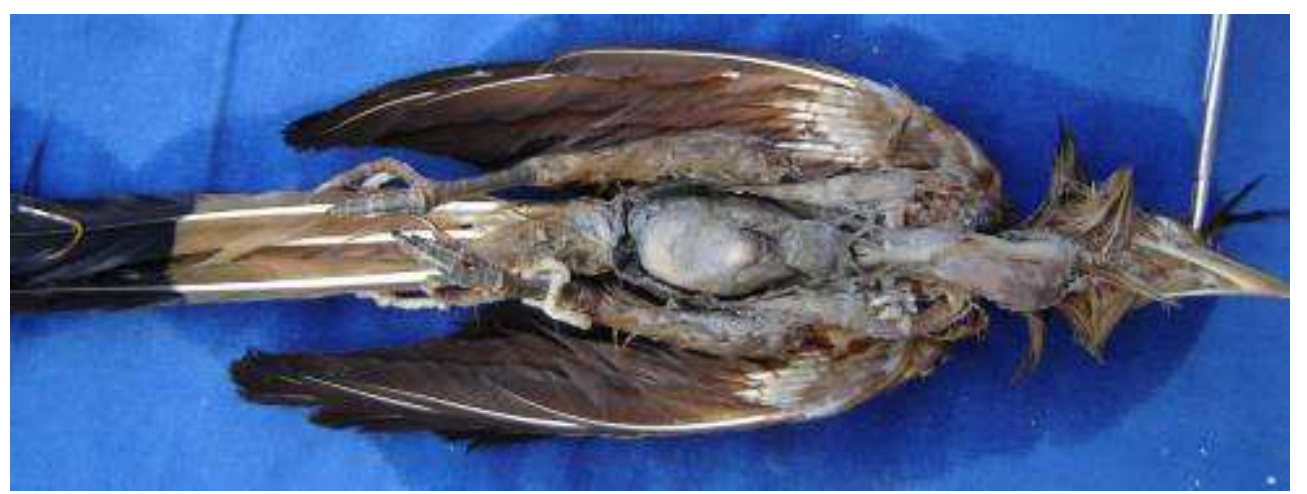

Figura 7: Anu-branco GuiraguiraGmelin, 1788 (CUCULIDAE).

O esôfago cervical tem início na face ventral do pescoço, dorsalmente à traquéia e logo no seu terço inicial desvia para o lado direito do pescoço, mantendo-se nessa posição durante toda sua trajetória, até a entrada da cavidade tóracoabdominal, onde se une à porção torácica, haja visto a ausência de inglúvio. Representa $8,70 \%$ do comprimento total da ave.

O esôfago torácico é mais comprido que a porção torácica equivalendo a $9,24 \%$ do comprimento total do representante. Inicialmente localiza-se dorsalmente à traquéia no antímero direito da cavidade, mas se desvia para esquerda e atinge a linha mediana à nível da bifurcação traqueal. Segue ventralmente ao pulmão e dorsalmente à base do coração unindo-se ao proventrículoa nível do terço médio do mesmo.

O estômago químico possui formato fusiforme, relaciona-se através da maior parte de sua face ventral ao fígado, principalmente lobo hepático esquerdo. Está situado ventralmente ao terço caudal do lobo pulmonar esquerdo e lobo renal cranial. Representa 3,58\% do comprimento total da ave.

O ventrículo é um órgão relativamente grande, equivalente a $6,96 \%$ do comprimento total do representante e possui formato arredondado. Sua face dorsal está relacionada a todos os segmentos do intestino delgado, com exceção das alças duodenais. Situa-se dorsalmente ao assoalho da cavidade tóracoabdominal. 
A porção cranial da alça duodenal localiza-se dorsalmente à porção caudal do lobo hepático esquerdo direito. A alça descendente do duodeno tem início na face lateral direita do ventrículo, segue caudolateralmente contornando o estômago muscular e se une à porção ascendente à nível da borda caudal do mesmo, através de uma curva em sentido cranial. Representa $7,80 \%$ do comprimento total da ave.

A alça ascendente do duodeno realiza trajetória oposta, lateralmente à porção descendente e se une ao segmento jejunoilíacoà nível da borda cranial do ventrículo, ventralmente ao lobo renal cranial direito. Equivale a $7,75 \%$ do comprimento total do representante.

Jejuno-íleo dispõe-se em alças unidas por mesentério, distribuídas no terço caudal da cavidade, dorsalmente ao ventrículo e ventralmente aos testículos e rins. Representa $28,96 \%$ do comprimento total da ave.

A divisão entre intestino delgado e intestino grosso é marcada por um par de cecos grandes, em forma de um curto segmento tubular da base até a metade de seu comprimento, a partir do qual apresenta-se em forma de uma bolsa alongada. Ambos se mantém unidos à porção final do segmento jejunoilíaco por mesentério. O ceco esquerdo está unido ao duodeno, e é maior que o direito. Representam respectivamente $5,31 \%$ e 3,90\% do comprimento total da ave.

O coloreto apresenta-se como um curto tubo reto, equivalente a $10,58 \%$ do comprimento total do representante. Segue ventralmente aos rins até a cloaca. 


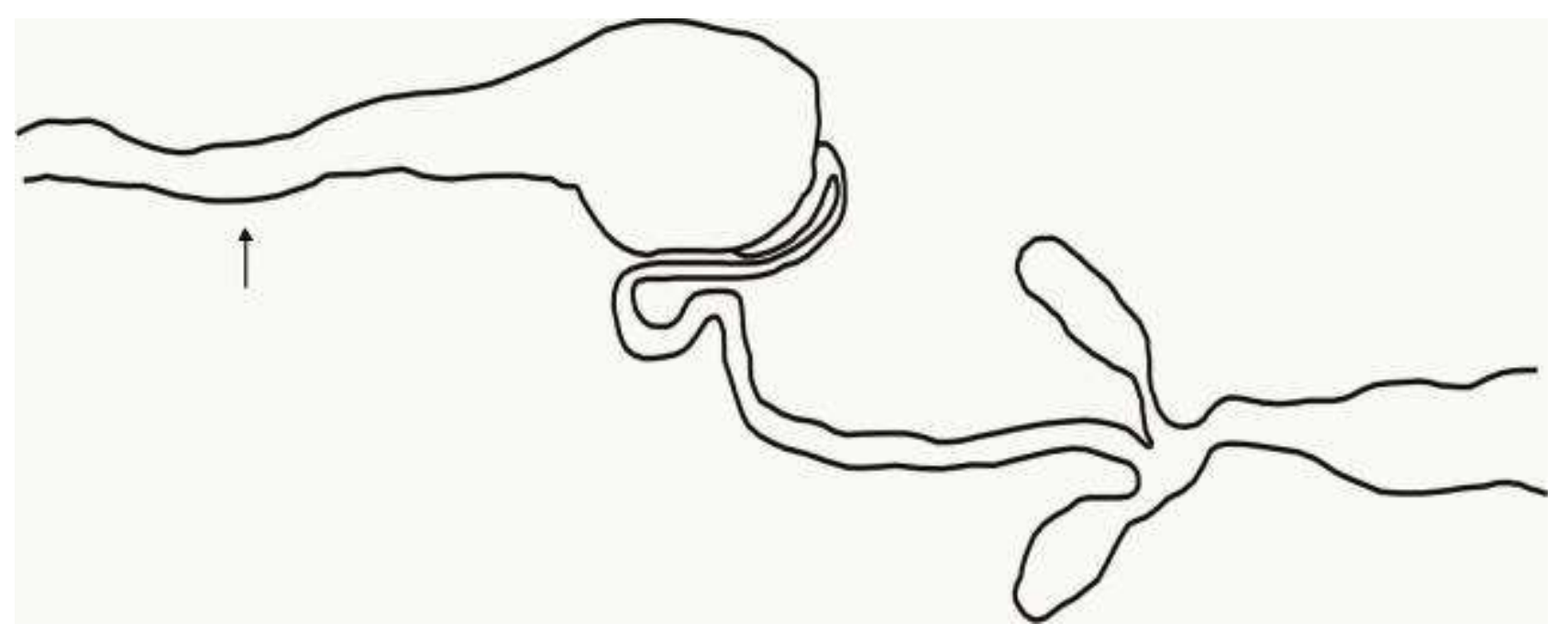

Figura 8: Vista ventral do tubo digestório de anu-branco. Transição entre esôfago cervical e esôfago torácico (seta preta).

Quadro 5: Medidas de comprimento e diâmetro,dos órgãos do tubo digestivo de anu-branco,

no 4

\begin{tabular}{|l|c|c|}
\hline \multicolumn{1}{|c|}{ Órgão } & Comprimento (mm) & Diâmetro (mm) \\
\hline Esôfago cervical & 33,50 & 5,80 \\
\hline Esôfago torácico & 35,60 & 7,50 \\
\hline Proventrículo & 13,80 & 10,15 \\
\hline $\begin{array}{l}\text { Ventrículo } \\
\text { Alça descendente do } \\
\text { duodeno }\end{array}$ & 30,05 & 4,75 \\
\hline $\begin{array}{l}\text { Alça ascendente do } \\
\text { duodeno }\end{array}$ & 29,85 & 3,75 \\
\hline Jejuno-íleo & 111,50 & 3,95 \\
\hline Ceco direito & 15,05 & 6,15 \\
\hline Ceco esquerdo & 20,45 & 7,25 \\
\hline Coloreto & 40,75 & 5,40 \\
\hline
\end{tabular}

- Comprimento X Largura X Espessura

\section{Ordem Sphenisciformes}

O representante utilizado para descrição anatômica nesta ordem foi:

Pingüim-de-magalhães Spheniscusmagellanicus Forster, 1781

(SPHENISCIDAE) 
O esôfago cervical inicia-se dorsalmente à traquéia, no antímero direito do pescoço. Mantém essa posição durante toda sua trajetória, até a entrada da cavidade abdominal, à nível do primeiro par de costelas, onde se une à porção torácica, haja visto a ausência de inglúvio. Representa $21,86 \%$ do comprimento total da ave.

O esôfago torácico segue dorsolateralmente à traquéia, dorsalmente à siringe, coração e metade cranial do lobo hepático esquerdo, até o estômago, à nível do terço caudal do lobo hepático esquerdo e lobo renal cranial esquerdo. Equivale a $30,32 \%$ do comprimento total do representante.

Essa espécie apresenta um grande estômago, de aspecto piriforme, que ocupa grande parte da região ventral da metade caudal da cavidade tóracoabdominal. Representa $20,24 \%$ do comprimento total da ave.

O intestino delgado é extenso, apresenta-se como inúmeros conjuntos de alças distribuídas pela cavidade em várias direções, ventralmente aos rins e dorsalmente ao estômago. Equivale a $71,11 \%$ do comprimento total do representante.

A divisão entre intestino delgado e intestino grosso é feita por um ceco, de formato cilíndrico, situado na face esquerda do segmento intestinal, que representa $5,10 \%$ do comprimento total da ave.

O coloreto é um segmento curto, reto, que tem início à nível do terço caudal do lobo renal esquerdo. Segue em posição paramediana esquerda até a cloaca e equivale a $4,96 \%$ do comprimento total do representante.

\section{DISCUSSÃO}

O esôfago é dividido anatomicamente em porção cervical, parte mais longa que segue dorsalmente à traquéia e retorna à linha média na porção imediatamente cranial à entrada torácica Rodenbusch, Canal e Santos (2004), e porção torácica, que passa sobre a bifurcação da traquéia e a base do coração e funde-se com o estômago glandular à esquerda do plano mediano (DUKE, 1996). Em nenhuma das ordens estudadas o esôfago cervical segue 
pela linha média do pescoço desviando-se caudalmente para o lado direito, como relatou Borges et al. (2004) e nem posicionado ventralmente à traquéia (MAPELI, 2003).

Nas ordens Anseriformes, Caprimulgiformes, Cuculiformes, Apodiformese Sphenisciformes a porção cervical tem início na face ventral do pescoço e logo no terço inicial desvia-se para o lado direito mantendo-se dorsalmente ou dorsolateralmente à traquéia, concordando com Juniper (1998).

No trabalho de Rodenbusch, Canal e Santos (2004), o esôfago torácico estende-se dorsalmente á traquéia, entre a siringe e a superfície ventral do pulmão até a base do coração e superfície dorsal do fígado coincidindo com nossos resultados. Segundo (DUKE, 1996) o esôfago torácico segue até a face medial do lobo hepático esquerdo, o que foi observado apenas nos Caprimulgiformes e Sphenisciformes. Nas ordens restantes, o esôfago torácico une-se ao proventrículo ao nível da extremidade cranial do lobo hepático esquerdo.

O estômago é dividido em proventrículo e ventrículo os quais são anatomicamente e fisiologicamente distintos conforme Juniper (1998) e essas características foram observadas em todas as ordens, exceto nos Sphenisciformes, os quais possuem apenas um estômago, que se apresenta como uma grande câmara, de aspecto piriforme, de acordo com a descrição de (LOODI,2003).

O proventrículo é pequeno e situa-se cranialmente ao grande ventrículo, separado do mesmo por uma distinta constrição, o istmo, como descreveu Mapeli (2003). Essa característica ocorreu apenas em Anseriformes. Entretanto os dois estômagos apresentam pouca divisão entre si nos Cuculiformes.

O estômago muscular é bem desenvolvido nos Anseriformes, justificando a observação feita por Borges et al.(2004) que afirmam ser o ventrículo altamente especializado em espécies que se nutrem de alimentos duros. Em todas as ordens, o diâmetro do seu eixo craniocaudal é maior que o dorsoventral, conforme relata Mapeli (2003). Este se encontra à esquerda da 
linha média e pode ser palpado imediatamente caudal ao esterno como foi observado na maioria das ordens, com exceção dos Apodiformes.

Nos Caprimulgiformes relaciona-se à superfície dorsal do lobo hepático esquerdo e em parte ao lóbulo direito como o descrito por LEMOS (1999).

Em geral, às alças intestinais e cecos localiza-se ventralmente às alças intestinais e cecos à alça duodenal, semelhante ao descrito por NICOLAU(2002).

Nas fêmeas da ordem Caprimulgiformes relacionam-se também ao ovário, conforme LEMOS (1999) descrevem.

Houve uma significativa variação de comprimento intestinal entre as ordens, bem como diferenças em posição e forma, sugerindo uma relação direta com o tipo de alimentação, conforme afirmam Duke (1996). Concordando com o fato de que valores relativos ao comprimento variam consideravelmente mesmo de espécie para espécie, Juniper (1998) considerou-se dimensões médias do segmento (em porcentagem) em relação ao comprimento total do(s) representante(s).

O duodeno é o segmento mais ventral entre as aves conforme Rodenbusch, Canale Santos (2004). Segundo estes autores, se estende da porção cranial da face lateral direita do ventrículo, característica observada em Apodiformes, já em relação Caprimulgiformes, emerge na face dorsolateral do mesmo.

Na maioria das ordens, a união da porção descendente com a porção ascendente do duodeno ocorre no nível do terço final do coloreto, ventralmente a este, com exceção dos Cuculiformes, onde através de uma curva dorsal, a união ocorre caudalmente ao estômago muscular, conforme já descrito por (LOODI, 2003 e MARÇAL Jr, 2003)

Segundo Borges et al. (2004) a alça ascendente do duodeno segue imediatamente dorsal à parte descendente, característica observada em Cuculiformes e Caprimulgiformes. Ainda segundo esses autores, a maior parte da porção ascendente situa-se próximo ao jejuno, à direita, e ao íleo e ceco 
esquerdo, dorsalmente, discordando do observado em Apodiformes e Anseriformes.

Nestes representantes, dispõe-se lateralmente à face direita da alça descendente do duodeno, mantendo contato com parte do segmento jejunoilíaco e parte do coloreto, mesmo nas ordens em que os representantes possuem cecos. É o segmento intestinal mais longo em todas as aves estudadas, conforme o exposto por Borges et al. (2004). Situa-se ventralmente aos rins e dorsalmente ao duodeno e estômago muscular concordando em parte com Chiquieri et al. (2003).

Observou-se que em Anseriformes, Cuculiformes e Caprimulgiformes o intestino grosso compreende um par de cecos e o cólon, como relatam Nicolau et al. (2002).

E ao contrário do que afirma MarçaL Jr (2003) os Apodiformes não apresentam cecos rudimentares pares, mas sim ausência total deste componente.

\section{CONCLUSÕES}

Conclui-se que nas ordens Anseriformes, Apodiformes, Caprimulgiformes, Cuculiformes e Sphenisciformes o esôfago cervical não segue pela linha média do pescoço desviando-se caudalmente para o lado direito; o estômago muscular é bem desenvolvido somente nos Anseriformes, e quando comparado as demais espécies o segmento jejunoilíaco intestinal é mais longo que as aves estudadas.

\section{REFERÊNCIAS}

BORGES, K. M.; ANDRADE, M. B.; OLEGÁRIO, M. M. M.; SILVA, C. B.; CASTRO, J. B.; CARVALHO, S. F. M.; SANTOS, A. L. Q. Descrição anatômica do tubo digestivo de frangod'água-azul (Porphyrula martinica - LINNAEUS, 1776). In: SEMANA ACADÊMICA DA UNIVERSIDADE FEDERAL DE UBERLÂNDIA, 1., 2004, Uberlândia. Anais... Uberlândia: UFU, 2004. 1CD-Rom. 
CHIQUIERI, J., SOARES, R.T.R.N., CARVALHO, E.C.Q., LEMOS, L.S. e VENTURA, B.G. (2003). Altura das vilosidades intestinais de suínos alimentados com rações contendo diferentes promotores de crescimento. In: 40o Reunião Anual da Sociedade Brasileira de Zootecnia. Anais...Santa Maria - RS. Cd Room.

COMITÊ BRASILEIRO DE REGISTROS ORNITOLÓGICOS. Listas das aves do Brasil. 10a edição de 25/01/2011. Disponível em <http://www.cbro.org.br>. Acesso em: 12 dez. 2011

DUKE, G. E. Digestão nas aves. In: DUKES, H. H. Dukes/Fisiologia dos animais domésticos. 11 ed. Rio de Janeiro: Guanabara Koogan, 1996. p. 390-397.

FLÔRES, M. L. et al. Surto de megabacteriose em canários-belgas (Serinus canária) em um criatório no estado do Rio Grande do Sul: relato de caso. Clínica Veterinária, São Paulo, v. 10, n. 54, p. 24-26, jan/fev. 2005.

JUNIPER, T.; PAN, M. Parrots - a guide to parrots of the world. New Haven: Yale University Press, 1998. 584 p.

LEMOS, M. Salmonella em aves silvestres no Jardim Zoológico do Rio de Janeiro, RJ. Revista Brasileira de Ciência Veterinária, Niterói, v. 6, n. 1, p. 40-43, jan/abr. 1999.

LOODI, M.M.. Probióticos, prebióticos e acidificante orgânico em dietas para frangos de corte. 52f. Tese (Doutorado em Zootecnia) - Faculdade de Ciências Agrárias e Veterinárias, Universidade Estadual Paulista, Jaboticabal.2003

NICOLAU, A. A. et al. O sevofluorano em psitacídeos (Amazona aestiva). Determinação da dose mínima (D.A.M) para produção de anestesia geral. Ciência Rural, Santa Maria, v. 32, n. 5, set/out. 2002.

MAPELI, E. B. Sistemática e parâmetros epidemiológicos de helmintos parasitos de jaós (Crypturellus undulatus), no estado do Mato Grosso do Sul (Pantanal de Paiaguás), e de codornas (Nothura maculosa) e nambuzinhos (Crypturellus parvirostris) no estado de São Paulo, 2003. 84 f. Dissertação (Doutorado) - Faculdade de Ciências Agrárias e Veterinárias, Universidade Estadual Paulista, Jaboticabal, 2003.

MARÇAL Jr., O. M.; FRANCHIN, A. G. Aves, do latim Avis. In: DEL-CLARO, K.; PREZOTO, F. As distintas faces do comportamento animal. Jundiaí: Livraria Conceito, 2003. p. 105-119

NICOLAU, A. A. et al. O sevofluorano em psitacídeos (Amazona aestiva). Determinação da dose mínima (D.A.M) para produção de anestesia geral. Ciência Rural, Santa Maria, v. 32, n. 5, set/out. 2002.

RODENBUSCH, C. R.; CANAL. C. W.; SANTOS, E. O. Hemossiderose e hemocromatose em aves silvestres - revisão. Clínica Veterinária, São Paulo, v. 9, n. 53, p. 44-50, nov/dez. 2004

SICK, H. Ornitologia brasileira. Rio de Janeiro: Nova Fronteira, 1997. 862 p. 